\title{
Defining Left bundle branch block-is this the roadblock to CRT delivery?
}

Left bundle branch block (LBBB) represents a composite of multiple mechanisms of impaired myocardial conduction that promote a variety of surface ECG morphologies reflected in a plethora of ECG diagnostic criteria which can be confusing (1-5).The QRS complex in LBBB reflects the failure of optimal myocardial recruitment achieved by the normal functioning His-Purkinje network, a manifestation of a suboptimal electrical coupling at one or multiple levels: within the left fascicles themselves, fascicular to myocardial conduction or intramyocardial conduction. The classic M wave pattern in V6 reflects the rotation of an activation wavefront in the left ventricle. Indeed, endocardial and more recently non-invasive ECG Imaging studies have demonstrated that there are 2 main patterns of activation-a Type 1 homogeneous depolarization and Type $2 \mathrm{U}$ shaped pattern as the activation wavefront rotates around a region of fixed or functional block (6-8). There has been a great deal of interest in attempting to predict the exact site of LBBB as this could have important implications not only for the siting of the coronary sinus LV lead but also predicting positive LV remodeling. A number of ECG markers of remodeling have been proposed including QRS duration, QRS area and the morphology of the intrinsicoid deflection (9-12). Fundamentally, if there is an excess of fibrosed myocardium, it is unlikely there is sufficient myocardial reserve to achieve adequate remodeling even if the lead is targeted outside scar.

In this edition xxx et al go back the basics, regarding the definition of LBBB and compare the ability of clinicians to accurately diagnose LBBB according to each of 4 commonest definitions. Not surprisingly, the most basic criteria (MADIT \& Strauss scores) focusing on 4 features were the most consistently correctly utilized in defining LBBB, although 1 in 10 ECGs were still classified differently by the same observer and for 1 in 5 ECGs, the cardiologists differed on clinical judgement or the score. The concern is that there was a large inter and intraobserver error for each LBBB definition amongst these very experienced clinicians. This has potentially very important implications for the prescription of CRT with the possibility that patients that could benefit may not receive a CRT if the more strict definitions are applied and the patients miscategorised.

A key issue in this paper is whether misjudging of LBBB pattern would have resulted in less CRT implants by these physicians in their daily practice and which ECG features are most commonly correctly applied. A deeper question is whether any of these definitions of LBBB impact on reverse remodeling. In the largest study to address this question examining 5 different LBBB classification schemes- it seems that QS or rS pattern in V1, notching/slurring in V5, V6 and absence of Q in V5, V6 are the most important remodelling criteria, whereas intrinsicoid time and $\mathrm{T}$ wave morphology seem to contribute less to the prediction of clinical response(13).

It is well recognised that the longer the QRS duration is in LBBB, the greater the remodelling effect of CRT will be with the largest responses occuring when QRS duration is $>150 \mathrm{~ms}$ (12). However, only a small proportion of patients have such broad QRS durations which has spurred investigation of other ECG markers to 
predict response even in non-LBBB cases. A recent study evaluated the QRS area which is an indicator of focal fibrosis in 1492 CRT recipients $(9,11)$. QRS area identified patients who did not experience the primary end point (death, transplantation, left ventricular assist device implantation) \& echocardiographic remodeling better than QRS morphology and QRS duration. QRS area was the only independent electrocardiographic determinant associated with the primary end point; hazard ratio, 0.50 (0.35-0.71) \& showed significant association with outcomes in both patients with and without LBBB and QRS $\geq 150 \mathrm{~ms}$.

Notching/slurring patterns in the precordial leads V1, V2, V5, and V6 and intrinsicoid deflection time are affected by the position of the heart in the chest and by appropriate positioning of electrodes [14]. These variations alter the LBBB/non-LBBB diagnosis, based on AHA/ACC/HRS, ESC 2006 and Strauss definitions. In addition, measurement of QRS duration has its uncertainties with differences that can exceed 10-15 ms- enough to be clinically significant for qualifying a patient for CRT. Therefore, there is a real need to develop a universally accepted standard of ECG classification for ventricular conduction disturbance, to be available as an ECG recording device industry standard, and to mandatorily prescribe its use in future CRT studies and in clinical practice guidelines.

With the advent of artificial intelligence \& machine learning algorithms, the ECG databases of the randomised CRT trials \& large cohorts could be re-examined to determine if there are specific derived higher order features of the digitized ECG that can provide a more sophisticated prediction of remodeling outcomes or more information on the burden of myocardial scar. For example the role of $Q$ wave location on the LBBB ECG or the predicted Q-LV time from lateral mid-QRS notching. This is increasingly relevant to the emergence of His Bundle pacing where intrinsic fascicular conduction \& normal fasicicular-myocardial coupling is critical to determining if His pacing will engage the distal conduction system to correct LBBB. The importance of this mechanism was elegantly illustrated in restoring a narrow QRS in LBBB patients with His pacing using ECG-Imaging (15). Such information would be of great value in determining who is most likely to benefit from His pacing as opposed to an LV lead, especially if there have been issues with coronary sinus LV lead placement due to difficult anatomy and an LV endocardial approach/surgical epicardial LV lead is being considered.

An automated ECG processing algorithm that accurately predicts the likelihood of benefit from His versus LV lead pacing could be developed to play a very useful cost-effective role in the pre-operative planning of CRT. Indeed if adequate long term cohort outcomes data were available combined with MR imaging data, then this digitized ECG analysis could be utilized to enable standardized \& tailored CRT with important applications in improving patient prognosis through patient selection and lead targeting hence minimisng the limitations of subjective assessments $(16,17)$. 


\section{References}

1. M. Brignole, A. Auricchio, G. Baron-Esquivias, et al.2013 ESC Guidelines on cardiac pacing and cardiac resynchronization therapy: the Task Force on cardiac pacing and resynchronization therapy of the European Society of Cardiology (ESC). Developed in collaboration with the European Heart Rhythm Association (EHRA)

Eur. Heart J., 34 (2013), pp. 2281-2329

2. B. Surawicz, R. Childers, B.J. Deal, et al.AHA/ACCF/HRS recommendations for the standardization and interpretation of the electrocardiogram: part III: intraventricular conduction disturbances: a scientific statement from the American Heart Association Electrocardiography and Arrhythmias Committee, Council on Clinical Cardiology; the American College of Cardiology Foundation; and the Heart Rhythm Society. Endorsed by the International Society for Computerized Electrocardiology

J. Am. Coll. Cardiol., 53 (2009), pp. 976-981

3. A. Bayés De Luna, V.N. Batchvarov, M. MalikChapter 1: the morphology of the electrocardiogram A.J. Camm (Ed.), The ESC Textbook of Cardiovascular Medicine, Blackwell Publishing (2006), pp. 1-35

4. F.G. Cosío, J. Palacios, A. Pastor, A. NúñezChapter 2 the electrocardiogram

A.J. Camm (Ed.), The ESC Textbook of Cardiovascular Medicine (2 Ed.), Oxford University Press (2009), pp. 29-83

5. D.G. Strauss, R.H. Selvester, G.S. WagnerDefining left bundle branch block in the era of cardiac resynchronization therapy. Am. J. Cardiol., 107 (2011), pp. 927-934

6. Fung JW, Yu CM, Yip G, Zhang Y, Chan H, Kum CC, Sanderson JE. Variable left ventricular activation pattern in patients with heartfailure and left bundle branch block. Heart. 2004 Jan;90(1):17-9.

7. Lambiase PD, Rinaldi A, Hauck J, Mobb M, Elliott D, Mohammad S, Gill JS, Bucknall CA. Noncontact left ventricular endocardial mapping in cardiac resynchronisation therapy. Heart. 2004 Jan;90(1):44-51.

8. Varma N, Jia P, Rudy Y. Electrocardiographic imaging of patients with heart failure with left bundle branch block and response to cardiac resynchronization therapy. J Electrocardiol. 2007 Nov-Dec;40(6 Suppl):S174-8.

9. Nguyên $\mathrm{UC}^{1}$, Claridge $\mathrm{S}^{2}$, Vernooy $\mathrm{K}^{3}$, Engels $\mathrm{EB}^{4}$, Razavi $\mathrm{R}^{5}$, Rinaldi $\mathrm{CA}^{2}$, Chen $\mathrm{Z}^{2}$, Prinzen

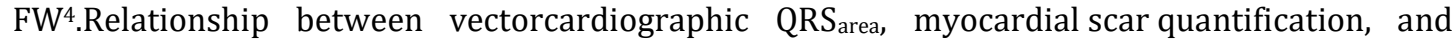
response to cardiac resynchronization therapy. J Electrocardiol. 2018 May - Jun;51(3):457-463. doi: 10.1016/j.jelectrocard.2018.01.009. Epub 2018 Feb 8.

10. Pastore G, Maines M, Marcantoni L, Zanon F, Noventa F, Corbucci G, Baracca E, Aggio S, Picariello C, Lanza D, Rigatelli G, Carraro M, Roncon L, Barold SS.

ECG parameters predict left ventricular conduction delay in patients with left ventricular dysfunction. Heart Rhythm. 2016 Dec;13(12):2289-2296. doi: 10.1016/j.hrthm.2016.07.010. Epub 2016 Jul 14.

11. van Stipdonk AMW, Ter Horst I, Kloosterman M, Engels EB, Rienstra M, Crijns HJGM, Vos MA, van Gelder IC, Prinzen FW, Meine M, Maass AH, Vernooy K.QRS Area Is a Strong Determinant of Outcome in Cardiac Resynchronization Therapy. Circ Arrhythm Electrophysiol. 2018 Dec;11(12):e006497. doi: 10.1161/CIRCEP.118.006497.

12. MO. Sweeney, R.J. vanBommel, M.J. Schalij, C.J. Borleffs, A.S. Hellkamp, J.J. Bax. Analysis of ventricular activation using surface electrocardiography to predict left ventricular reverse volumetric remodeling during cardiac resynchronization therapy 
13. Caputo ML, van Stipdonk A, Illner A, D'Ambrosio G, Regoli F, Conte G, Moccetti T, Klersy C, Prinzen FW, Vernooy K, Auricchio A. The definition of left bundle branch block influences the response to cardiac resynchronization therapy. Int J Cardiol. 2018 Oct 15;269:165-169. doi: 10.1016/j.ijcard.2018.07.060. Epub 2018 Jul 17.

14. U.C. Nguyên, M. Potse, F. Regoli, et al.An in-silico analysis of the effect of heart position and orientation on the ECG morphology and vectorcardiogram parameters in patients with heart failure and intraventricular conduction defects J. Electrocardiol., 48 (2015), pp. 617-625

15. Arnold AD, Shun-Shin MJ, Keene D, Howard JP, Sohaib SMA, Wright IJ, Cole GD, Qureshi NA, Lefroy DC, Koa-Wing M, Linton NWF, Lim PB, Peters NS, Davies DW, Muthumala A, Tanner M, Ellenbogen KA, Kanagaratnam P, Francis DP, Whinnett ZI. His Resynchronization Versus Biventricular Pacing in Patients With Heart Failure and Left Bundle Branch Block. J Am Coll Cardiol. 2018 Dec 18;72(24):3112-3122. doi: 10.1016/j.jacc.2018.09.073.

16. Khan FZ, Virdee MS, Palmer CR, Pugh PJ, O'Halloran D, Elsik M, Read PA, Begley D, Fynn SP, Dutka DP. Targeted left ventricular lead placement to guide cardiac resynchronization therapy: the TARGET study: a randomized, controlled trial.

J Am Coll Cardiol. 2012 Apr 24;59(17):1509-18. doi: 10.1016/j.jacc.2011.12.030. Epub 2012 Mar 7.

17. Chen Z, Sohal M, Sammut E, Child N, Jackson T, Claridge S, Cooklin M, O'Neill M, Wright M, Gill J, Chiribiri A, Schaeffter T, Carr-White G, Razavi R, Rinaldi CA.

Focal But Not Diffuse Myocardial Fibrosis Burden Quantification Using Cardiac Magnetic Resonance Imaging Predicts Left Ventricular Reverse Modeling Following Cardiac Resynchronization Therapy. J Cardiovasc Electrophysiol. 2016 Feb;27(2):203-9. doi: 10.1111/jce.12855. Epub 2015 Dec 17 